\title{
EFFECT OF SURFACING TECHNOLOGY ON CORROSION RESISTANCE OF DEPOSTED METAL AS APPLIED TO CONDITIONS OF SERVICE OF HYDRAULIC EQUIPMENT PARTS*
}

\author{
Yu.M. KUSKOV ${ }^{1}$, V.A. ZHDANOV ${ }^{1}$, V.A. TISHCHENKO ${ }^{1}$, M.M. STUDENT ${ }^{2}$ and N.R. CHERVINSKAYA ${ }^{2}$ \\ ${ }^{1}$ E.O. Paton Electric Welding Institute, NASU \\ 11 Kazimir Malevich Str., 03680, Kiev, Ukraine. E-mail: office@paton.kiev.ua \\ ${ }^{2}$ G.V. Karpenko Physical-Mechanical Institute, NASU \\ 5 Nauchnaya Str., 79601, Lvov, Ukraine
}

\begin{abstract}
Corrosion resistance of metal of 30Kh20MN and 30Kh22MN types, produced by submerged arc surfacing using different techniques and technologies of surfacing was investigated. The feasibility of increasing the corrosion resistance of the deposited metal by proper selection of the surfacing technology was found. The best results on corrosion resistance were obtained in a pulsed surfacing using flux-cored wire at its feeding with $0.5 \mathrm{~Hz}$ pulse. The results of investigations can be used in restoration of worn-out parts and manufacture of the new ones of hydraulic equipment. 6 Ref., 2 Tables, 5 Figures.
\end{abstract}

Keywords : submerged arc surfacing, technology of surfacing, pulsed feeding of wire, deposited metal, corrosion

Many parts of equipment, installed in salt and coal mines and used in public services, are operated under the complex conditions of abrasive wear and corrosion effect. The most known representatives of these parts are the rods, plungers of hydraulic equipment, in particular, of mine hydraulic props of mechanized piles and supporting shields of tunneling machines. To increase the service life of these parts, their working surfaces are already protected during manufacturing by using galvanic coatings, mainly of chromium type. The thickness of the deposited layer is usually 5-50 $\mu \mathrm{m}$, and hardness (for chrome) is HV 800-1000. In spite of their high wear-resistant and anti-corrosion properties the galvanic coatings are not durable and their density and, respectively, resistance to corrosion and wear are decreased with time.

Figure 1 shows the corrosion damages on chrome-plated surface of the rod after service in a coal mine. It should be also noted, that deposition of galvanic coatings on the working surface is ecologically dangerous process, which is refused in many industrialized countries.

One of the methods, allowing restoration of rods and plungers and return of hydraulic machines into service is the submerged arc surfacing (Figure 2).
The earlier experiments on surfacing, as well as investigations on modeling of deposited metal behavior in different synthetic media (in particular, water of coal mines) showed that metal of martensite-ferrite class of $30 \mathrm{Kh} 20 \mathrm{MN}$ and $30 \mathrm{Kh} 22 \mathrm{MN}$ types possesses good protective properties (depending on service conditions). Hardness of this deposited metal can be regulated in the ranges of HRC 35-48. However, in some cases during the service process and even at a long storage of deposited products in open rooms the dark circular

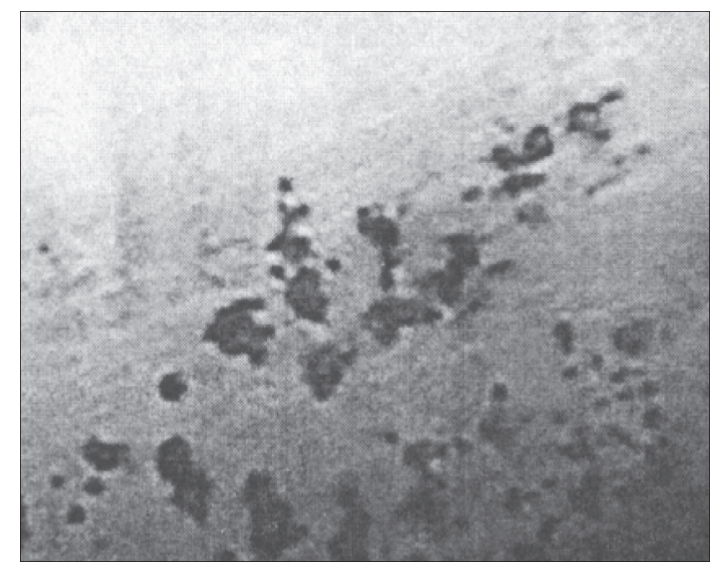

Figure 1. Corrosion damages on chrome-plated surface of rod after service in a coal mine

\footnotetext{
${ }^{*}$ On the materials of the work performed in the frames of the target program of the NAS of Ukraine «Problems of live and service safety of structures, constructions and machines» (2013-2015).
} 


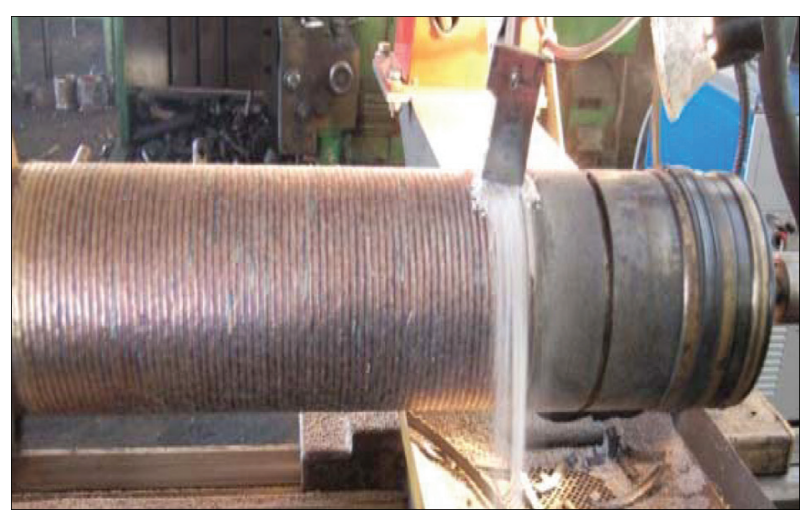

Figure 2. Process of submerged arc surfacing of plunger of mine hydraulic props

bands, corresponding to zones of overlapping beads, deposited by a helical line, appeared on the deposited surfaces. Probably, this is connected with that the metal of zone of overlapping the neighboring beads is located in a hazardous region of temperatures $\left(680-780{ }^{\circ} \mathrm{C}\right)$. And, depending on time of duration in this region the conditions of proceeding the diffusion processes are changed with a possible formation of chemical and structural heterogeneity in metal $[1,2]$ and, respectively, by reduction in its resistance to corrosion.

Coming from that the metal of $30 \mathrm{Kh} 20 \mathrm{MN}$ and $30 \mathrm{Kh} 22 \mathrm{MN}$ types is characterized by rather high values of service properties, it was decided to provide their optimum level by testing these metals using surfacing by different technological procedures. Moreover, this approach to the selection of metal being deposited was stipulated by its relatively simple chemical composition as compared, for example, with the metal $08 \mathrm{Kh} 20 \mathrm{~N} 10 \mathrm{G} 7 \mathrm{~T}$, recommended for surfacing of mine props, and has lower content of expensive nickel by one order (at more than twice increased hardness). At the first stage of investigations the following surfacing procedures, as optimum ones, were selected:

- surfacing in one layer with a large overlapping of beads for $1 / 2$ of their width. In accordance with work [1], such technique of surfacing can improve the structure and chemical homogeneity;

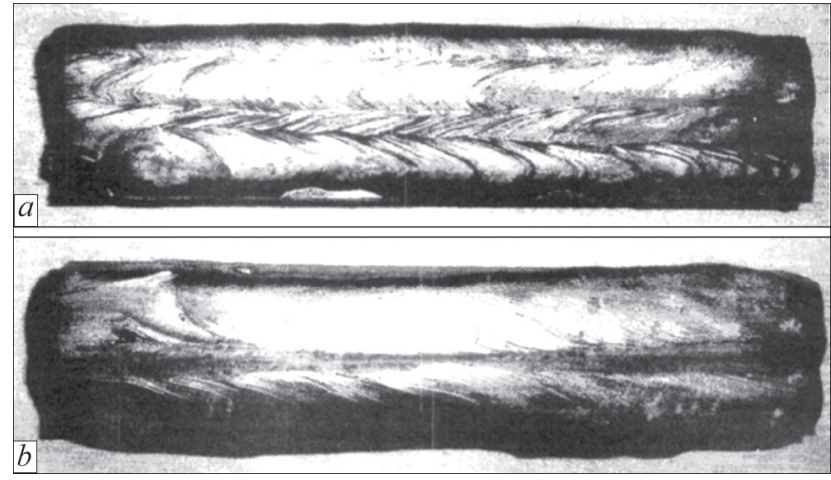

Figure 3. Specimens deposited by flux-cored wire PP-Np$30 \mathrm{Kh} 20 \mathrm{MN}$ in one $(a)$ and three $(b)$ layers
Table 1. Conditions and results of a pulsed surfacing of single-layer metal 30Kh20MN

\begin{tabular}{|c|c|c|}
\hline Specimen & $\begin{array}{c}\text { Pulse of wire } \\
\text { feeding, Hz }\end{array}$ & $\begin{array}{c}\text { Hardness } \\
\text { of deposited } \\
\text { metal } H R C\end{array}$ \\
\hline 11 & 2.5 & $50-52$ \\
\hline 22 & 3.3 & $53-56$ \\
\hline 33 & 1.1 & $51-52$ \\
\hline 44 & 0.5 & $48-50$ \\
\hline
\end{tabular}

- surfacing in three layers with a misaligned overlapping of beads. Taking into account that the wear of working surface usually does not exceed $2 \mathrm{~mm}$, the surfacing in three layers allows producing thickness for more than $2 \mathrm{~mm}$, but in this case the heating of lower layers is more uniform. The drawback of this technology is the surfacing of excess metal with its subsequent removal by the mechanical treatment;

- surfacing with a pulsed feeding of the flux-cored wire. The pulsed electrode wire feeding is performed by using a mechanism, based on a quasi-wave converter [3]. From the data of works [4, 5] the reduction in heat input into the deposited metal occurs due to a pulsed feeding of the electrode wire and the more favorable structure is formed.

As far as during surfacing of rods and plungers it is necessary to provide a minimum penetration of the base metal (this is especially important in making a single-layer surfacing) and minimum thickness of the deposited metal, then the diameter of the fluxcored wire is accepted to be $2.2 \mathrm{~mm}$. As a base metal the steel $40 \mathrm{Kh}$ was selected in the form of a sheet of $40 \mathrm{~mm}$ thickness. It was supposed that results, obtained in surfacing of horizontal surface of the specimen, will correspond to the results of a circumferential surfacing of cylindrical parts at a precise keeping of the parameters of the surfacing process conditions. Surfacing in a conventional condition: $I=250 \mathrm{~A}$, $U=30 \mathrm{~V}, v_{\mathrm{s}}=18 \mathrm{~m} / \mathrm{h}$; in a pulsed condition: pulse of wire feeding is $0.5-3.3 \mathrm{~Hz}, U=30 \mathrm{~V}, I=250 \mathrm{~A}$, $v_{\mathrm{s}}=15 \mathrm{~m} / \mathrm{h}, \mathrm{AN}-26$ flux.

The appearance of specimens, deposited by fluxcored wire PP-AN205 (PP-Np-30Kh20MN) at conventional and pulsed modes is given in Figures 3 and 4. The conditions of surfacing (pulses, Hz) and hardness of a single-layer deposited metal $30 \mathrm{Kh} 20 \mathrm{MN}$ at a pulsed feeding of the flux-cored wire are given in Table 1.

Testing of specimens of deposited metal on corrosion resistance was performed in unit SVA-1BM of G.V. Karpenko PhMI. Corrosion processes were studied by using potentiostats PI-50-1 and IPC-Pro. For potentiostat IPC-Pro the program IPC 2000 was used, which is applied for hardware complex «Potentiostat IPC-Pro + PC IBM PC». 

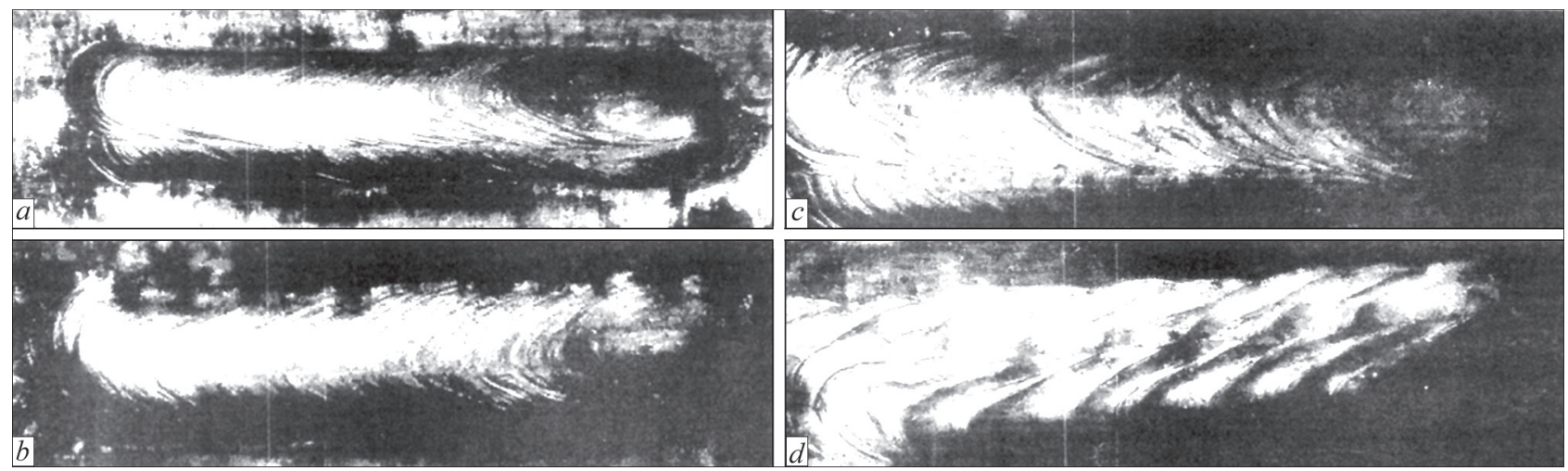

Figure 4. Specimens deposited by flux-cored wire PP-Np-30Kh20MN with superposition of pulses of its feeding: $a-2.5 ; b-3.3$; $c-1.1 ; d-0.5 \mathrm{~Hz}$

Table 2. Values of corrosion (before and after polarization tests) of single-layer metal 30Kh20MN, deposited in a pulsed mode

\begin{tabular}{|c|c|c|c|c|}
\hline \multirow{2}{*}{ Values of corrosion } & \multicolumn{4}{|c|}{ Specimen } \\
\hline & 11 & 22 & 33 & 44 \\
\hline$E_{\text {stab }}, \mathrm{mV}$ & -415 & -473 & -457 & -582 \\
\hline$E_{\text {corr }}, \mathrm{mV}$ & -379 & -463 & -466 & -441 \\
\hline$i_{\text {corr }} \cdot 10^{-3}, \mathrm{~mA} / \mathrm{cm}^{2}$ & 3.06 & 4.99 & 3.8 & 1.44 \\
\hline
\end{tabular}

Note. Evaluation of specimen surface quality after 10-day soaking in $\mathrm{NaCl}$ solution showed that traces of corrosion are observed on specimens 11, 22 and 33, while the traces of corrosion are not observed on specimen 44 .

To study the processes, occurring as a result of contact of materials being studied and corrosion medium, the method of voltammeter measurements was applied, allowing revealing the specifics of proceeding the electrochemical reactions on the surface of the material studied in the process of its interaction with a preset corrosion medium. In this case the basic characteristic, by which the systems «material-medium» was evaluated, was a polarization curve. This is dependence of current density $i$ on potential $E$ of
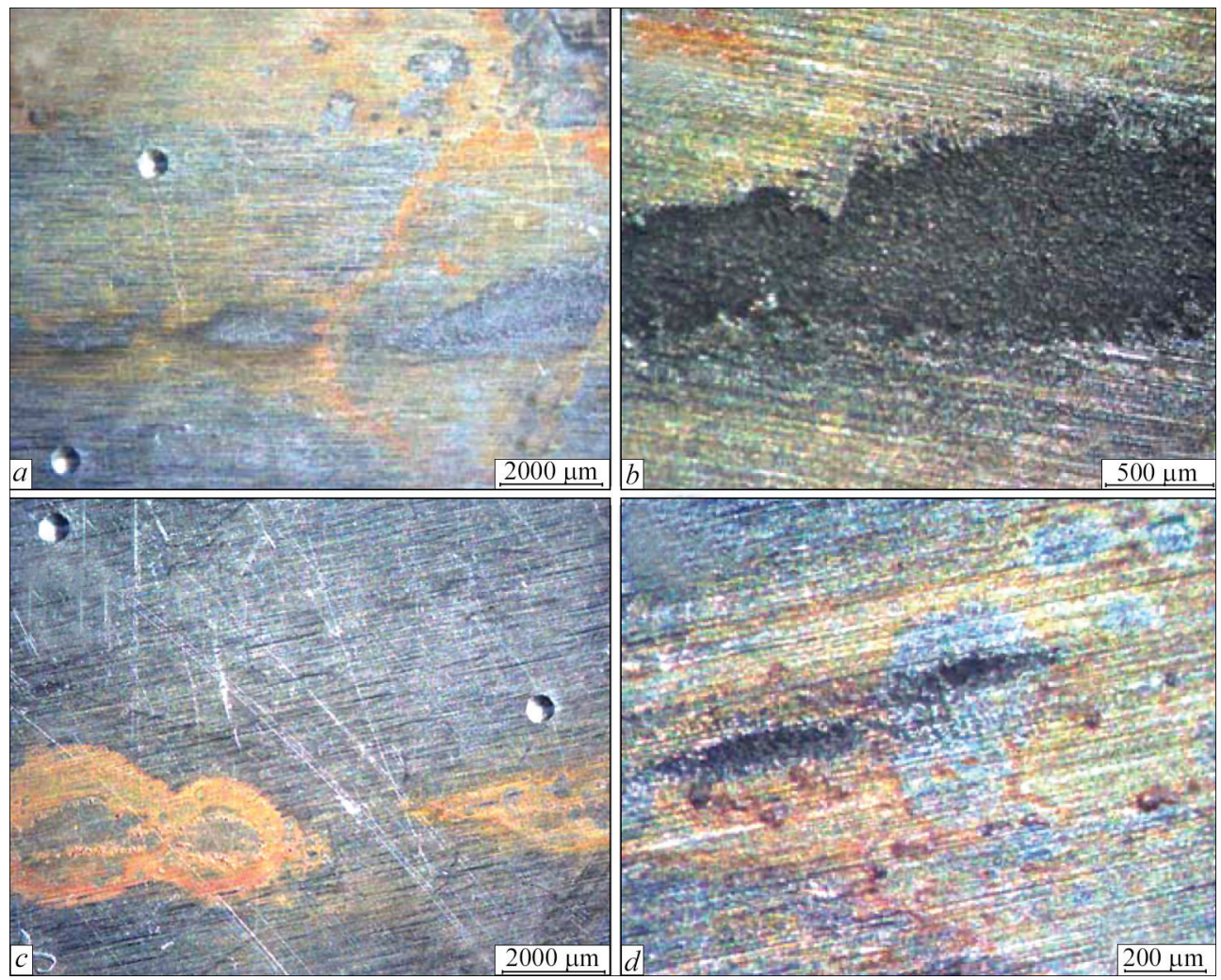

Figure 5. Surface of specimens, deposited in a pulsed mode, after corrosion tests: $a, b-$ specimen $22 ; c, d-44$ 
the studied surface. The polarization curves were taken in a potentiodynamic mode, maximum reflecting the pattern of real processes proceeding on the studied surface [6]. Electrode processes of investigated specimens, being working electrodes, in corrosion medium were measured as compared with saturated chloride-silver electrode. An auxiliary electrode was a platinum grid. Rate of potential scanning was $2 \mathrm{mV} / \mathrm{s}$.

The investigations were carried out in electrochemical cell in medium of $3 \%$ water solution of $\mathrm{NaCl}$. Before the polarization tests the specimens were soaked in this solution for 10 days.

The best results on corrosion resistance were obtained on specimens deposited in a pulsed mode at the value of $0.5 \mathrm{~Hz}$. The effect of the pulse value on proceeding the corrosion process is given in Table 2.

Figure 5 shows the surfaces of specimens 22 and 44 after polarization tests. As is seen from Figure 5, $b$ after the polarization tests the significant corrosion damages of surface of specimen 22 are observed. On the surface of specimen 44 the minimum local zones of damage can be detected at a large magnification (Figure 5,d). Thus, the value of a pulse of wire feeding in surfacing can have a great influence on corrosion processes in the deposited metal.

\section{Conclusions}

1. The feasibility of improvement of deposited metal corrosion resistance by a proper selection of technique and technology of surfacing by the same surfacing material was found.

2. The best values of corrosion resistance of the deposited metal of $\mathrm{C}-\mathrm{Cr}-\mathrm{Ni}-\mathrm{Mo}$ system are attained in a single-layer pulsed submerged arc surfacing with a flux-cored wire at the $0.5 \mathrm{~Hz}$ pulse of its feeding.

3. Results of carried out investigations can be applied in restoration of hydraulic equipment worn-out parts and manufacture of new ones, in particular rods and plungers.

1. Kondratiev, I.A., Vasiliev, V.G., Dzykovich, I.Ya. (1996) Investigation of structure heterogeneity of $35 \mathrm{~V} 9 \mathrm{Kh} 3 \mathrm{SF}$ type deposited metal and its influence on serviceability of built-up mill rolls. Avtomatich. Svarka, 6, 17-20.

2. Palchuk, N.Yu. (1954) Effect of heating in manual welding on intercrystalline corrosion of welds of 18-8 type steels. Ibid., 3, 41-49.

3. Lebedev, V.A. (1996) Control of rate and pitch of pulse electrode wire feed in mechanisms based on quasi-wave converter. Ibid., 6, 34-37.

4. Lebedev, V.A., Tishchenko, V.A. (2013) Examination of heat-affected zone in mechanized surfacing with mode modulation. Remont, Vosstanovlenie, Modernizatsiya, 10, 29-34.

5. Kryukov, A.V., Pavlov, N.V., Zelenkovsky, A.A. (2013) Peculiarities of welding with pulse electrode wire feed. Tekhnologiya Mashinostroeniya, 7, 30-31.

6. Zhuk, N.P. (1976) Course of theory of corrosion and protection of metals. Moscow: Metallurgiya.

Received 22.12.2015 